\title{
The Primates 2020 Most-Cited Paper Award
}

\author{
Tetsuro Matsuzawa ${ }^{1}$
}

Published online: 21 October 2020

(C) Japan Monkey Centre and Springer Japan KK, part of Springer Nature 2020

The four papers listed below were jointly the most frequently cited in 2019 among those published in Primates during the period from 2017 to 2018 . Their authors thus contributed greatly to enhancing the reputation of our journal. For this achievement, each author will receive declarations attesting to their contributions.

Lynne A. Isbell, Stephanie F. Etting: Scales drive detection, attention, and memory of snakes in wild vervet monkeys (Chlorocebus pygerythrus) (Isbell and Etting 2017).

Erica M. Tennenhouse, Sarah Putman, Nicole P. Boisseau, Janine L. Brown: Relationships between steroid hormones in hair and social behaviour in ring-tailed lemurs (Lemur catta) (Tennenhouse et al. 2017).

Fany Brotcorne, Gwennan Giraud, Noëlle Gunst, Agustín Fuentes, I. Nengah Wandia, Roseline C. Beudels-Jamar, Pascal Poncin, Marie-Claude Huynen, Jean-Baptiste Leca: Intergroup variation in robbing and bartering by long-tailed macaques at Uluwatu Temple (Bali, Indonesia) (Brotcorne et al. 2017).

Zhi-Pang Huang, Matthew B. Scott, Yan-Peng Li, GuoPeng Ren, Zuo-Fu Xiang, Liang-Wei Cui, Wen Xiao: Blackand-white snub-nosed monkey (Rhinopithecus bieti) feeding behavior in a degraded forest fragment: clues to a stressed population (Huang et al. 2017).
September 2020

Tetsuro Matsuzawa:

Gen'ichi Idani:

Naofumi Nakagawa:

Toshiro Mikami:
Editor-in-Chief, Primates General Director, Japan Monkey Centre

President, Primate Society of Japan Executive Editor, Springer, a part of Springer Nature

\section{References}

Brotcorne F, Giraud G, Gunst N, Fuentes A, Wandia IN, Beudels-Jamar RC, Poncin P, Huynen MC, Leca JB (2017) Intergroup variation in robbing and bartering by long-tailed macaques at Uluwatu temple (Bali, Indonesia). Primates 58:505-516. https://doi.org/10.1007/ s10329-017-0611-1

Huang ZP, Scott MB, Li YP, Ren GP, Xiang ZF, Cui LW, Xiao W (2017) Black-and-white snub-nosed monkey (Rhinopithecus bieti) feeding behavior in a degraded forest fragment: clues to a stressed population. Primates 57:517-524. https://doi.org/10.1007/s1032 9-017-0618-7

Isbell LA, Etting SF (2017) Scales drive detection, attention, and memory of snakes in wild vervet monkeys (Chlorocebus pygerythrus). Primates 58:121-129. https://doi.org/10.1007/s10329-016-0562-y

Tennenhouse EM, Putman S, Boisseau NP, Brown JL (2017) Relationships between steroid hormones in hair and social behaviour in ring-tailed lemurs (Lemur catta). Primates 58:199-209. https:// doi.org/10.1007/s10329-016-0566-7

Publisher's Note Springer Nature remains neutral with regard to jurisdictional claims in published maps and institutional affiliations.

Tetsuro Matsuzawa

matsuzawa.tetsuro.8w@kyoto-u.ac.jp

1 Kyoto University, Kyoto, Japan 

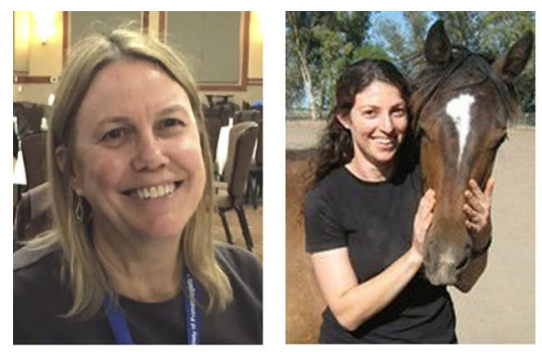

From the left: Lynne A. Isbell, Stephanie F. Etting
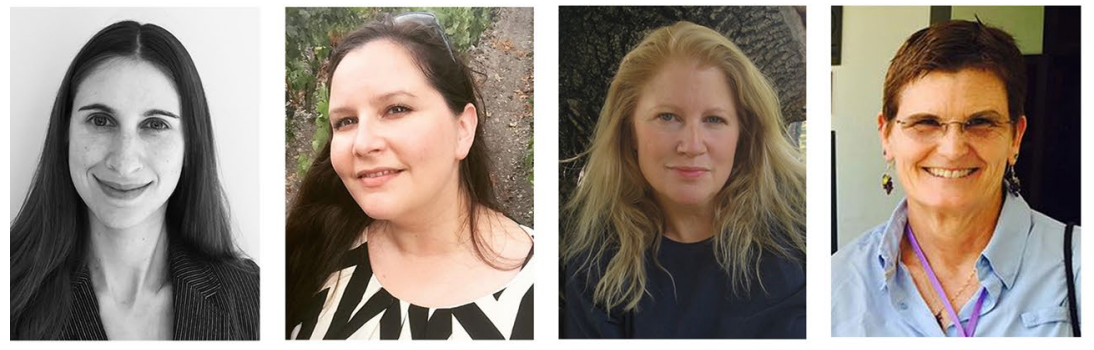

From the left:

Erica M. Tennenhouse

Sarah Putman

Nicole P. Boisseau

Janine L. Brown
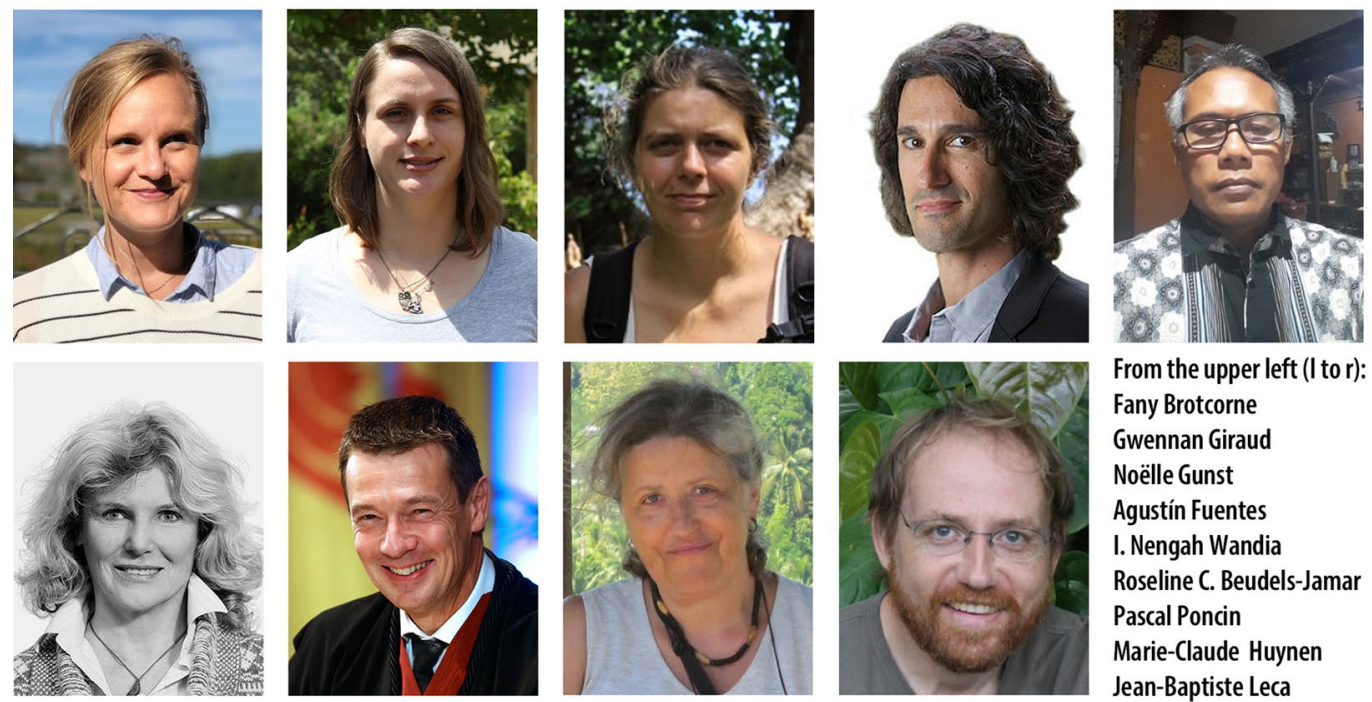

From the upper left (I to r):

Fany Brotcorne

Gwennan Giraud

Noëlle Gunst

Agustín Fuentes

I. Nengah Wandia

Roseline C. Beudels-Jamar

Pascal Poncin

Marie-Claude Huynen

Jean-Baptiste Leca
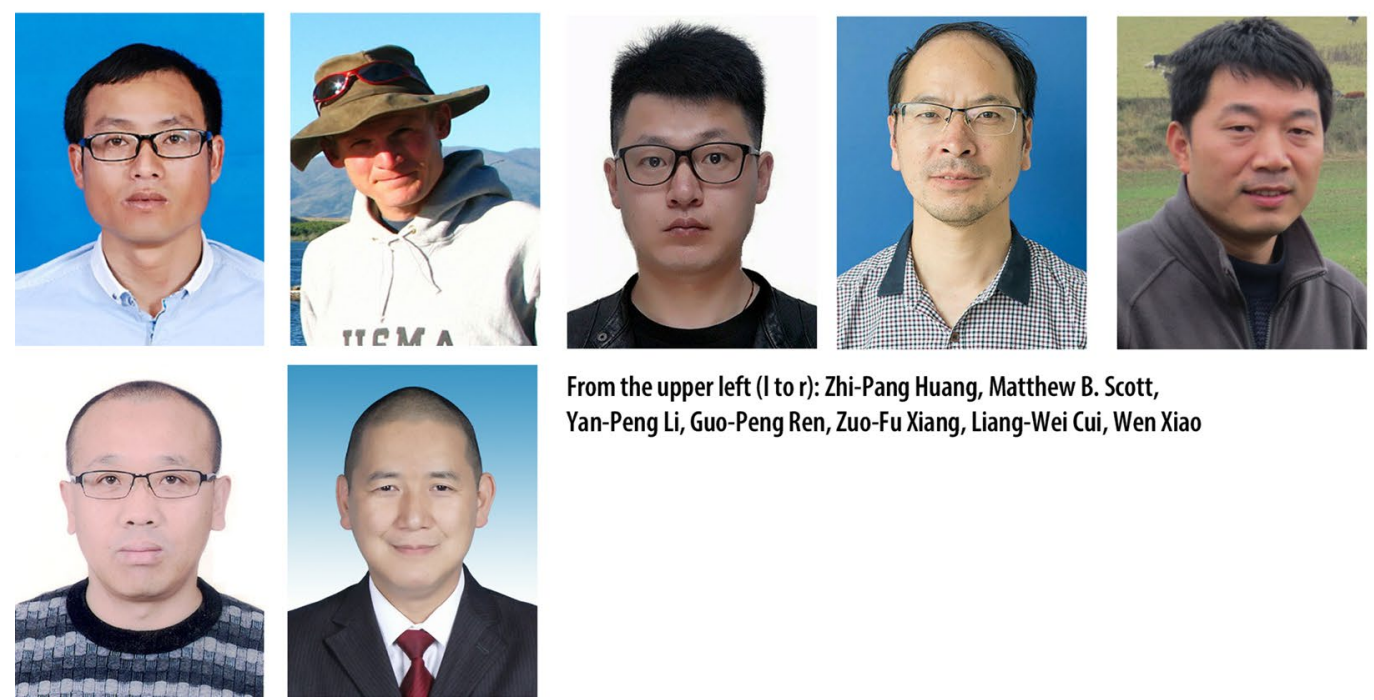

From the upper left (I to r): Zhi-Pang Huang, Matthew B. Scott,

Yan-Peng Li, Guo-Peng Ren, Zuo-Fu Xiang, Liang-Wei Cui, Wen Xiao 